\title{
Probable autochthonous introduced malaria cases in Italy in 2009-2011 and the risk of local vector-borne transmission
}

R Romi (roberto.romi@iss.it) ${ }^{1}$, D Boccolini' ${ }^{1}, M_{\text {Menegon }}^{1}$, G Rezza ${ }^{1}$

1. Istituto Superiore di Sanità (ISS), Department of Infectious, Parasitic and Immune-Mediated Diseases (MIPI), Rome, Italy

Citation style for this article:

Romi R, Boccolini D, Menegon M, Rezza G. Probable autochthonous introduced malaria cases in Italy in $2009-2011$ and the risk of local vector-borne transmission. Euro Surveill. 2012;17(48):pii=20325. Available online: http://www.eurosurveillance.org/ViewArticle.aspx?Articleld=20325

Article submitted on o9 November 2012 / published on 29 November 2012

We describe two cases of probable autochthonous introduced Plasmodium vivax malaria that occurred in 2009 and 2011 in two sites of South-Central Italy. Although the sources of the infections were not detected, local transmission could not be disproved and therefore the cases were classified as autochthonous. Sporadic $P$. vivax cases transmitted by indigenous vectors may be considered possible in some areas of the country where vector abundance and environmental conditions are favourable to malaria transmission.

Two probable autochthonous introduced cases of Plasmodium vivax malaria were notified from two sites in South-Central Italy in 2009 and 2011. We report on the possible risk of local vector-borne malaria transmission in areas in Italy where the vector abundance and environmental conditions are favourable to malaria transmission.

Although soon after the World War II malaria was eliminated from Mediterranean countries, the rise in the average temperature of the earth [1], environmental modifications, the increase of international travel, and socio-economic constraints recorded in the last decades [2], have raised the concern about the possible re-emergence of malaria in some of these countries, such as Italy, where malaria had been endemic before [3].

However, the presence of competent vectors and of reservoirs of the parasites, i.e. humans carrying gametocytes in their blood may play a major role in malaria re-emergence. The recent outbreaks of malaria in Greece, although limited in size, are paradigmatic of this possible public health threat [4].

In Italy, since the five-year eradication campaign in 1947-1951, one single confirmed case of autochthonous introduced $P$. vivax malaria (transmitted by an indigenous vector) [5], has been recorded in Grosseto, Tuscany Region in 1997 [6]. Hereby, we report two probable but not proved autochthonous introduced [5] malaria cases that occurred in Italy in the last three years, namely between 2009 and 2011.

\section{Case reports}

Case 1

A 41-year-old Caucasian man living in the outskirts of Rome was admitted to the intensive care unit of the local Hospital for Infectious Diseases on 8 August 2009 with high remittent fever, peaking every 48 hours and classical paroxysms with alternate cold, hot and sweating stages. Clinical suspicion of malaria was confirmed by microscopic (blood smear observation, thick and thin films) and molecular (nested PCR analysis) [7] diagnosis as $P$. vivax malaria. The patient had no history of recent travel in malaria-endemic areas; he only reported a one-week holiday in 2003 in Santo Domingo, Dominican Republic (where foci of malaria still exist in limited areas) and in 2004 in Sharm el Sheikh, Egypt, but he didn't undertake any malaria prophylactic treatment on these occasions. He had no history of blood transfusions, tissue/organ transplantation, intravenous drug use, and no event of high fever in the previous six years. In July 2009, the month before the onset of symptoms, he had spent two weeks in two different holiday farms, one in Terracina, between 4 and 5 July, and the other in Pontinia, between 25 and 26 July. Both sites are located in the former 'Pontine marshes', a rural coastal plain of Central Italy, where malaria was hyperendemic until 1946. Although long term $P$. vivax relapses have been reported [8] and could not be entirely ruled out in this case, the short stay in Santo Domingo and the lack of a history of febrile attacks shortly after the travel made unlikely the hypothesis of a travel-acquired infection and oriented towards the hypothesis of an autochthonous case. After the detection of this case, the search for potential sources of infection (i.e. gametocyte carriers), was directed to the identification of migrants from endemic countries. A large number of regular migrants from India and Sri Lanka, employed in buffalo rearing and 
horticulture in green houses, in a site which was very close to both holiday farms but no malaria case was identified among these people in 2009, through the regular surveillance system.

Considering a minimum of 10-12 days for the development of the sporogonic cycle of $P$. vivax into the insect and another 8-10 days for the onset of symptoms, malaria infection was probably acquired in the first half of July. Due to the late notification of the case to our reference centre at Istituto Superiore di Sanità, the entomological investigation started one month after malaria diagnosis. One Anopheles maculpennis s.s. engorged female was collected from one of the animal shelters in the farms. Potential breeding sites suitable for anopheline larvae (few small canals for water supply in agriculture) were investigated but no mosquitoes or larvae were found. The entomological investigation conducted around the house of the patient in Rome also gave negative results (no adult of anopheline mosquitoes or suitable larval breeding sites were found).

\section{Case 2}

A 39-year-old Caucasian man resident in the midtown of Rende, a residential district close to the town of Cosenza, in Calabria Region, southern Italy, was hospitalised on 15 September 2011 with the same symptoms as Case 1 (high remittent fever, peaking every 48 hours and classical paroxysms with alternate cold, hot and sweating stages), although the onset of symptoms had been on 1 September. Microscopic and molecular diagnosis of $P$. vivax malaria was performed as reported above. The patient did not report any blood transfusions, tissue/organ transplantation and intravenous drug use, and no remarkable febrile attacks during the previous six years. In his travel history he reported no recent travel in malaria-endemic areas, but a holiday in the Island of Santorini, Greece, in 2003 and a cruise along the coasts of the Mediterranean Sea in 2005. In August 2011, he spent the weekends in the village of Scalea, located along the Tyrrhenian coast, where there are some historically productive breeding sites where both An. labranchiae and An. superpictus occur [9]. Two investigations were carried out around the summer house in Scalea and in the area of the habitual residence in Rende to identify the source of infection but no gametocyte carriers were found. Three reception centres for African and Asian refugees, located in Cosenza Province, were not considered in our investigation because they were more than $10 \mathrm{~km}$ away from both houses of the index case and because the refugee people were under medical control (i.e. they were screened for infectious diseases upon arrival in Italy and had easy access to medical care when sick).

The infection was probably acquired in mid-August, and the entomological investigation conducted on 27 and 28 September (a couple of weeks after malaria diagnosis) in the town of Scalea, revealed the presence of a possible anopheline breeding site in a canal that

FIGURE 1

Annual imported malaria cases and gametocyte carriers ${ }^{\mathrm{a}}$, Italy, 2000-2011

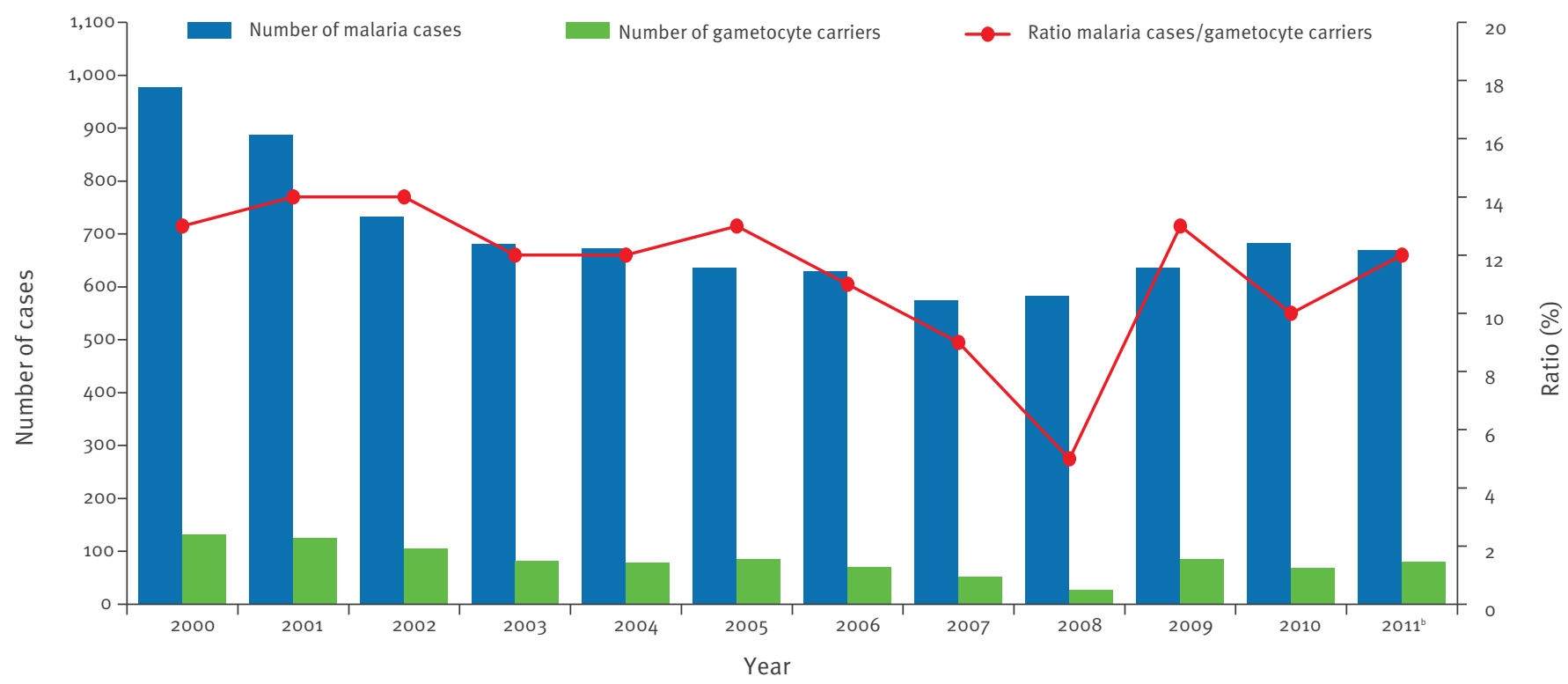

\footnotetext{
Gametocyte carriers have blood smears positive for malaria parasites, showing, among the other haematic forms of the Plasmodium, the gametocytes, the only form able to infect the anopheline vector (in Italy they are all imported cases that may act as reservoirs of the disease).

b Data for 2011 are provisional.

Source: Istituto Superiore di Sanità and Ministry of Health, Italy.
} 
Distribution of the potential malaria vectors and regions considered at risk of malaria reintroduction, Italy, 2005-2011

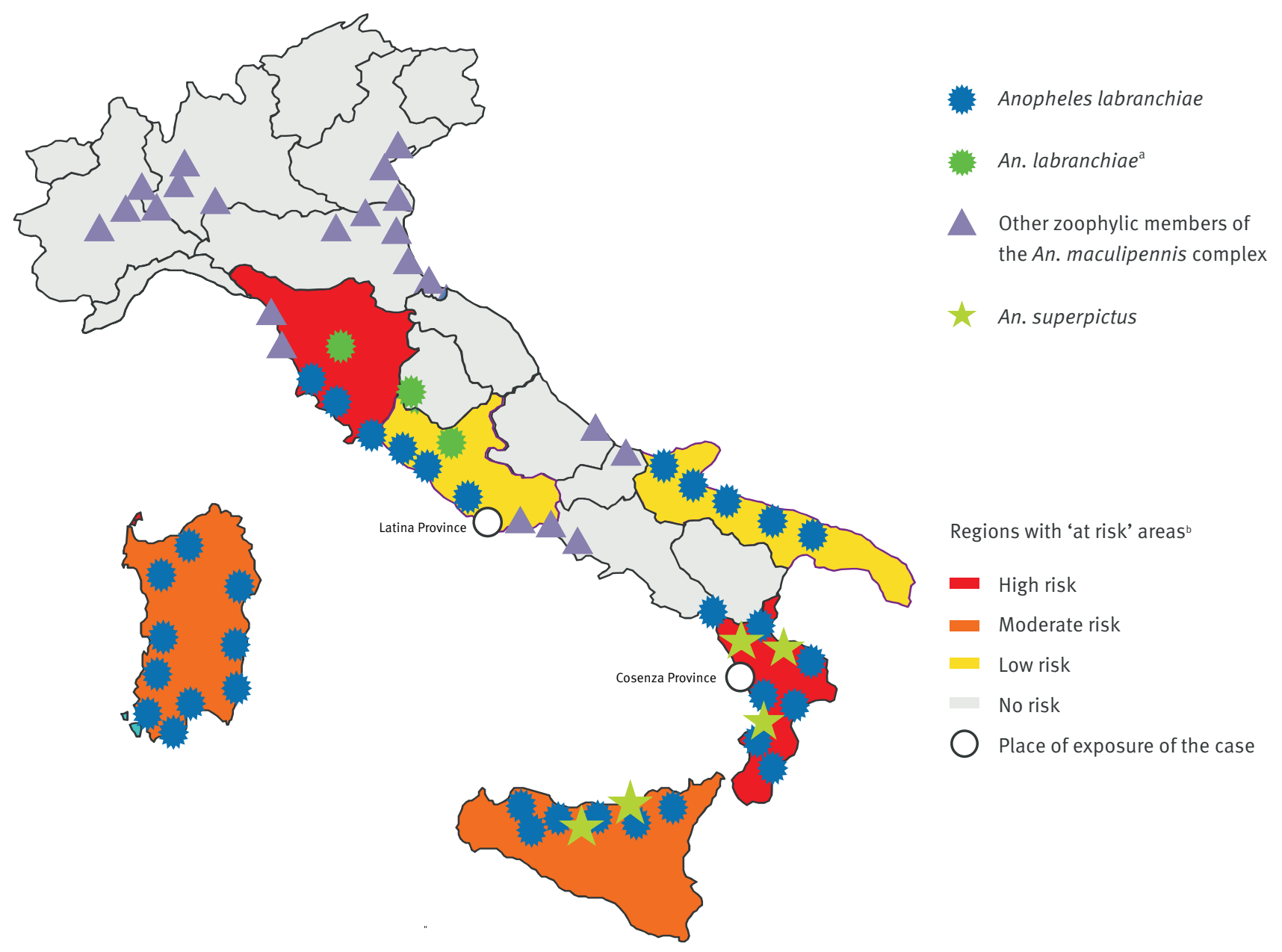

a First detected in 2010-2011 in northern-central Italy.

b Areas with presence of foci and seasonal abundance of the potential vector and with seasonal climatic conditions favourable to malaria transmission.

crossed the plain area of the town before flowing into the sea, close to the house of the patient. The canal was almost dry, with few residual pools of water along the edges, due to the presence of heavy vegetation. No anopheline larvae were found in those pools. Among the animal shelters inspected, only one resulted positive for anopheline mosquitoes: two engorged females of An. labranchiae were found in a cow shed of a farm located about $600 \mathrm{~m}$ from the summer residence of the patient. In Rende, only a single animal shelter was detected in the surrounding of the habitual residence: it was a small goat shelter located in a public garden about $200 \mathrm{~m}$ away from the case's house, where 26 Anopheles mosquitoes belonging to the An. maculipennis complex were found, 21 of which were identified as An. labranchiae by ITS2 sequence analysis [10]. One An. maculipennis s.s. IV instar larva was found in one of the two streams which were considered suitable breeding sites, located at $150 \mathrm{~m}$ and $600 \mathrm{~m}$ from the case's house, respectively.

\section{Discussion}

During the last 15 years (1997-2011), a total of 17 possible autochthonous cases of malaria occurred in Italy. Only one of them was likely transmitted by local vectors, thus fitting the criteria for an introduced case [5]. Other 14 cases were attributed to either iatrogenic transmission (nosocomial infection $(n=7)$, post-transfusion $(n=3)$, and post-transplant $(n=1))$ or bites from infected mosquitoes imported with baggage $(n=3)$ [11]. The remaining two cases, discussed in this report, were classified as autochthonous [5]. In fact, although they can potentially be considered cases of introduced malaria transmitted by indigenous vectors, the source of infection remains undefined.

In Italy, as well as in other Mediterranean countries recently investigated for the risk of malaria reintroduction, the return to a situation of endemic malaria is unlikely, but the occurrence of sporadic, isolated cases of introduced $P$. vivax malaria may still be considered 
possible $[12,13]$. Even if the vulnerability of the Italian territory during the summer months seemed to be very low between 2000 and 2011 as shown in Figure 1, recent entomological surveys carried out in areas historically considered 'at risk' for malaria showed a remarkable presence (or even high abundance in some places) of the main indigenous vector An. labranchiae, and confirmed its ability to bite humans both in the presence and in the absence of alternative hosts, indoors as well as outdoors [12-14].

A map displaying the current distribution of the potential malaria vectors and the regions of the country considered 'at risk', based on our own recent field collected data (2005-2011), is showed in Figure 2.

It should also be stressed that several direct or indirect effects of human activities in rural areas may quickly modify the distribution and the abundance of the vectors and may promote the contacts between mosquitoes and gametocyte carriers; these factors, together with the presence of a large non-immune human population, may have an impact on malaria reintroduction in a newly vulnerable area [14].

In the light of the recent malaria outbreaks that occurred in Greece, the two cases reported here stress the importance of vigilance for this disease and the need to improve existing epidemiological and entomological surveillance systems for malaria.

Finally, it should be mentioned that the occurrence of cases of autochthonous transmission of exotic vectorborne infections in Europe may concern infections other than malaria. The recent outbreaks that occurred in some European countries such as Italy (West Nile and Chikungunya viruses) France, Croatia, and Portugal (Dengue virus) [15-20], and the widespread presence and abundance of the potential vectors of these diseases in our country, represent a clear threat to the public health which needs adequate countermeasures.

\section{Acknowledgments}

We thank Dr. C. Gnesivo (Department of Prevention, Local Health Unit Rome D), Dr F. Perelli and Dr I. Valentini (Department of Prevention, Local Health Unit of Cosenza), Dr. F. Fabiano (Direttore UOC Igiene Pubblica-Medicina Preventiva, Cosenza), Dr. F. Cesario (Department of Infectious Diseases, Hospital of Cosenza), Dr. P. Cavalcanti (Laboratory of Microbiology, Hospital of Cosenza), Dr. F. Pagnotta (Veterinary Services of the Local Health Unit of Cosenza) for their precious support in both logistic organisation and epidemiological inquiries. Special thanks to A. Carinci and F. Severini (MIPI Department, Istituto Superiore di Sanità) for their efficient, quick and kind help in editing this article.
3. Takken W, Knols BGJ. Emerging pests and vector-borne diseases in Europe. Ecology and control of vector-borne diseases. Volume 1. Wageningen (The Netherlands): Wageningen Academic Publishers; 2007.

4. Danis K, Baka A, Lenglet A, Van Bortel W, Terzaki I, Tseroni $M$, et al. Autochthonous Plasmodium vivax malaria in Greece, 2011. Euro Surveill. 2011;16(42):pii=19993. Available from: http://www.eurosurveillance.org/ViewArticle. aspx?Articleld=19993

5. World Health Organization (WHO). Terminology of malaria and malaria eradication. Report of a Drifting Committee. Geneva: WHO. 1963. Available from: http://apps.who.int/iris/ bitstream/10665/39007/1/9241540141.pdf

6. Severini C, Cuccagna P, Fiorilli G, Allegri MP, Buriani C, Toti M. Malaria in Maremma, Italy. Lancet. 1998;351(9111):1246-7.

7. Snounou G, Singh B. Nested PCR analysis of Plasmodium parasites. Methods Mol Med. 2002;72:189-203.

8. Durante Mangoni E, Severini C, Menegon M, Romi R, Ruggiero G, Majori G. Case report: An unusual late relapse of Plasmodium vivax malaria. Am J Trop Med Hyg. 2003;68(2):159-60.

9. Romi R, Sabatinelli G, Majori G. Could malaria reappear in Italy? Emerg Infect Dis. 2001;7(6): 915-19.

10. Di Luca M, Boccolini D, Marinucci M, Romi R. Intra-population polymorphism in Anopheles messeae (An. maculipennis complex) inferred by molecular analysis. J Med Entomol. 2004;41(4):582-6.

11. Romi R, Boccolini D, D’Amato S, Cenci C, Pompa MG, Majori G. Malaria surveillance in Italy: the 2000-2008 national pattern of imported cases. Italian J Trop Med. 2010;15(1-4): 35-8.

12. Di Luca M, Boccolini D, Severini F, Toma L, Barbieri FM, Massa A, et al. A 2-year entomological study of potential malaria vectors in Central Italy. Vector Borne Zoonotic Dis. 2009;9(6):703-11.

13. Romi R, Boccolini D, Vallorani R, Severini F, Toma L, Cocchi M, et al. Assessment of the risk of malaria re-introduction in the Maremma Plain (Central Italy) using a multi factorial approach. Malaria J. 2012;11:98.

14. Boccolini D, Toma L, Di Luca M, Severini F, Cocchi M, Bella A, et al. Impact of environmental changes and human-related factors on the potential malaria vector, Anopheles labranchiae (Diptera: Culicidae), in Maremma, Central Italy. J Med Entomol. 2012:49(4):833-42.

15. Rezza G, Nicoletti L, Angelini R, Romi R, Finarelli AC, Panning $M$, et al. Infection with chikungunya virus in Italy: an outbreak in a temperate region. Lancet. 2007;370 (9602):1840-6.

16. Gould EA, Gallian P, De Lamballerie X, Charrel RN. First cases of autochthonous dengue fever and chikungunya fever in France: from bad dream to reality! Clin Microbiol Infect. 2010;16(12):1702-4.

17. La Ruche G, Souarès $Y$, Armengaud A, Peloux-Petiot F, Delaunay $P$, Desprès $P$, et al. First two autochthonous dengue virus infections in metropolitan France, September 2010. Euro Surveill. 2010;15(39): pii=19676. Available from: http://www. eurosurveillance.org/ViewArticle.aspx?Articleld=19676

18. Grandadam $M$, Caro V, Plumet $S$, Thiberge JM, Souarès $Y$, Failloux $A B$, et al. Chikungunya virus: Southeastern France. Emerg Infect Dis. 2010;17(5):910-3.

19. Gjenero-Margan I, Aleraj B, Krajcar D, Lesnikar V, Klobučar A, Pem-Novosel I, et al. Autochthonous dengue fever in Croatia, August-September 2010. Euro Surveill. 2011;16(9):pii=19805. Available from: http://www.eurosurveillance.org/ViewArticle. aspx?Articleld $=19805$

20. European Centre for Disease Prevention and Control (ECDC). Communicable Disease Threats Report (CDTR). Week 43, 21-27 October 2012. Stockholm: ECDC. Available from: http://www. ecdc.europa.eu/en/publications/Publications/ECDC_CDTR_ week43.pdf

\section{References}

1. Gould EA, Higgs S. Impact of climate change and other factors on emerging arbovirus diseases. Trans R Soc Trop Med Hyg. 2009;103(2):109-21.

2. Vora N. Impact of anthropogenic environmental alterations on vector-borne diseases. Medscape J Med. 2008;10(10):238-44. 